\title{
EXPERIENCIAS DE USO DE SOFTWARE LIBRE PARA LA GESTIÓN TERRITORIAL DEL CENTRO HISTÓRICO DE LA HABANA VIEJA.
}

\author{
Asier Mediavilla, Beñat Abajo, Juan Pérez, Isabel Rodríguez-Maribona, \\ Julio Portieles, Eritk Guerra, Patricia Rodríguez Alomá \\ LABEIN -Tecnalia \\ Dirección de Cooperación Internacional (Oficina del Historiador de La Habana) \\ Dirección de Informática y Comunicaciones (Oficina del Historiador de La Habana) \\ Dirección del Plan Maestro de Revitalización Integral del Centro Histórico
}

Remisión Artículo: 18-5-2007

Palabras Clave: Gestión Territorial, patrimonio histórico, conectividad

Resumen: La Oficina del Historiador de la Ciudad de La Habana (en adelante $\mathrm{OHCH}$ ), consciente de la creciente penetración de las Tecnologías de la Información y las Comunicaciones en la sociedad pretende, mediante la implantación del sistema aquí descrito, dotar a sus numerosas entidades y también al público en general de un potente sistema de información territorial que realice una gestión integral del territorio, considerando aspectos de patrimonio histórico, medio ambiente, aspectos sociales y de calidad de vida y administrativos, entre otros y ayude en la toma de decisiones. Se ha apostado fuertemente por la utilización de software libre en las soluciones planteadas a la par que se ha mejorado la conectividad de las entidades, contando con el soporte tecnológico de LABEIN-Tecnalia.

\section{Introducción}

La Oficina del Historiador de la Ciudad de la Habana es el organismo territorial responsable de promover y dirigir el proceso de transformación integral del Centro Histórico de La Habana, favoreciendo a través de sus múltiples acciones no sólo la recuperación del patrimonio tangible sino también lo relativo al medio cultural, socioeconómico y ambiental de este singular sitio, el cual cuenta con alrededor de 3500 edificaciones, la séptima parte de las cuales es considerada de gran valor histórico y patrimonial.

En los últimos 10 años, la $\mathrm{OHCH}$ ha desarrollado un proceso de gestión integral del territorio a su cargo. Para ello ha creado y consolidado una estructura organizativa con direcciones especializadas y empresas, capaces de conducir este complejo proceso de recuperación integral.

Una entidad clave dentro de la $\mathrm{OHCH}$ es el Plan Maestro, cuya misión es estudiar la problemática del Centro Histórico y definir las estrategias más convenientes para su recuperación y desarrollo, contando con un equipo multidisciplinar en el que se canaliza la toma de decisiones. El Plan Maestro es la principal fuente de información para otras entidades que componen la $\mathrm{OHCH}$.

Otra de las entidades que componen esta estructura es la Dirección de Informática y Comunicaciones (DIC), creada en el 2005, para garantizar un uso eficiente de las Tecnologías de la Información y las Comunicaciones (TIC).

Entre las principales estrategias de trabajo de la DIC están: 
- Fortalecimiento de la infraestructura tecnológica y logística de intercambio de datos entre las instituciones de la OHC. Esto incluye el mejoramiento de las redes de datos, servidores y equipos de comunicación, así como, la ampliación de los servicios que estos soportan.

- Diseño y Desarrollo de aplicaciones GIS que puedan ser utilizadas como apoyo al proceso la planificación, gestión y toma de decisiones del territorio.

- Desarrollo de aplicaciones que permitan mejorar las condiciones de vida de los habitantes del territorio, así como agilizar y hacer más transparente la gestión pública de la OHC.

- Diversificación de la economía local a través del desarrollo de productos de software que apoyen la promoción y difusión de los valores históricos y patrimoniales del Centro Histórico de la Ciudad.

- Trabajar de forma continua para elevar la formación y capacidades de los especialistas en temas relacionados con las ciencias informáticas.

De toda esta estrategia de desarrollo, se derivan tareas y lineamientos de trabajo específicos, muchos de los cuales son apoyados por diferentes actores y modalidades de Cooperación al Desarrollo.

\section{Origen del proyecto}

En los últimos tiempos la $\mathrm{OHCH}$ ha ido creciendo de forma importante tanto a nivel humano como por su campo de acción, de forma que cada vez se maneja un mayor volumen de información procedente de diversas fuentes, con lo que la gestión de información es compleja. A este factor hay que añadir la dispersión de las entidades de la $\mathrm{OHCH}$, que aunque cercanas físicamente en el entorno de La Habana Vieja, no comparten inmueble, por lo que la comunicación no es siempre la óptima.

Con estos antecedentes, unidos a la cada vez mayor implantación de las TIC en la sociedad, la $\mathrm{OHCH}$ ha visto necesario fortalecer el Sistema de Gestión interno de cara a dar respuesta a las cada vez mayores necesidades, centrándose en dos ejes:

- Resolver el problema de la fragmentación de la $\mathrm{OHCH}$ mediante la mejora de la conectividad entre las principales sedes a través de una red de datos de fibra óptica, robusteciendo así el intercambio de información.

- El segundo objetivo principal, y en el que se centra este trabajo, es la implantación de un Sistema de Información Territorial que realice una gestión integral del territorio, centralizando toda la información relativa a datos de los inmuebles (información administrativa, estado de conservación, características arquitectónicas, proyectos de rehabilitación llevados a cabo) así como aspectos medioambientales, sociales y turísticos. No olvidemos que el objetivo final de la rehabilitación del patrimonio es también la mejora de las condiciones de vida de la población y el uso racional de los bienes gestionados. Se está desarrollando un sistema basado en Sistemas de Información Geográfica (SIG) implementado en una plataforma Web, cuya facilidad de uso y potencial visual hace del mismo una eficaz herramienta para la toma de decisiones y administración de la información. 
Para ello la $\mathrm{OHCH}$ ha puesto en marcha el presente proyecto, en el que ha contado el soporte de LABEIN-Tecnalia en aspectos tecnológicos. Además, se ha contado con la cofinanciación del Gobierno Vasco, el cual dispone de un programa llamado Fondo de Cooperación y Ayuda al Desarrollo (FOCAD), que es el principal instrumento a través del cual se canalizan los programas de solidaridad internacional y de cooperación pública, ejecutados por diversas entidades vascas en colaboración con entidades situadas en países en vías de desarrollo.

Las principales líneas de acción del programa FOCAD son la dotación de infraestructuras y asistencia técnica, formación, educación y ayudas humanitarias entre otros, varias de las cuales van en consonancia con el objetivo del proyecto.

\section{Descripción del Sistema}

El sistema que se describe a continuación va dirigido tanto a especialistas internos de la OHC que necesiten consultar una información determinada, o cuando corresponda, poder actualizarla, como también a usuarios externos (publico en general, turistas...) que quieran obtener información del Centro Histórico (hoteles, lugares de interés, museos, etc.). En una primera fase se pretende conseguir una herramienta eficaz para uso interno de la $\mathrm{OHCH}$. Una vez se haya comprobado su éxito a nivel interno y se haya mejorado la conectividad de cara al exterior se extenderá al público en general.

Una de las características más destacadas del Sistema es la apuesta decidida en la utilización de soluciones basadas en software libre, las cuales garantizan la sostenibilidad del proyecto a través de la reducción de costes y la posibilidad de contar con una amplia comunidad de desarrolladores que permite el intercambio de experiencias y la difusión de conocimientos.

El núcleo de la aplicación lo constituye el Sistema de Información Territorial (SIT) del Centro Histórico, donde de manera dinámica se puede mostrar u ocultar información de redes hidrográficas y de transporte, límites territoriales y municipales, zonas verdes, etc. Además, en función del nivel de zoom permite visualizar datos más específicos como nombres de calles, plazas y parques, códigos postales, parcelas y otros. Junto a ello las tradicionales herramientas de escala, zoom y selección. Sobre esta base se han desarrollado dos aplicaciones, que son la de Potencial de Desarrollo (Inventario de Inmuebles) y la de Proyectos de Cooperación.

La primera de ellas está pensada como herramienta de trabajo en la planificación y gestión territorial por parte del Plan Maestro para la Revitalización Integral del Centro Histórico. Esta aplicación permite realizar consultas complejas a la información cartográfica. Por ejemplo, es posible buscar inmuebles en función de la combinación de determinados criterios como los datos de la parcela (localización, superficies máximas y mínimas...), características arquitectónicas (tipología, grado de conservación...), usos de suelo, nombres de calles y otros. 


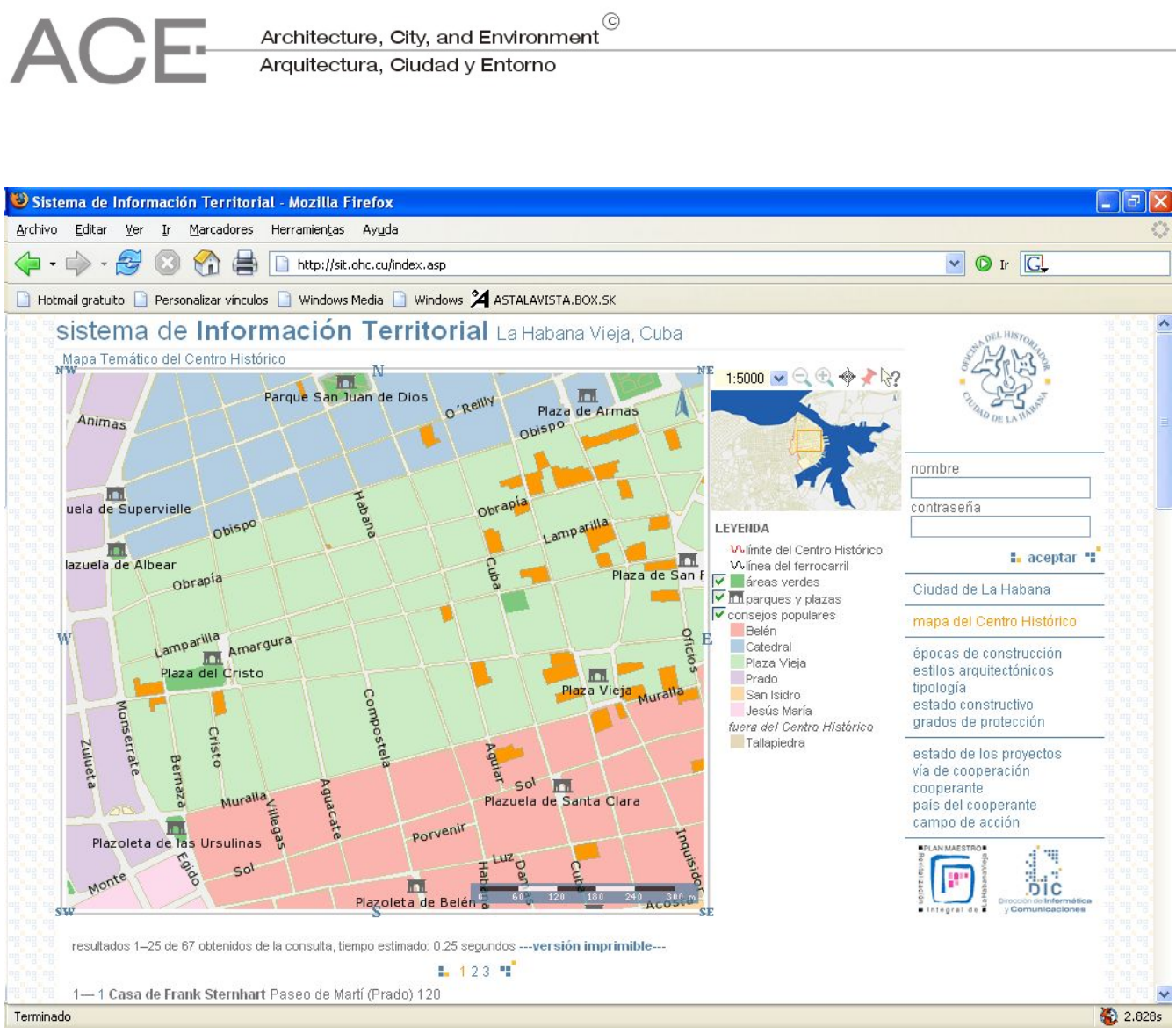

Figura 1. Interfaz Web del SIT.

Este tipo de consulta devuelve un mapa con los inmuebles resaltados (Figura 1), así como un listado en forma de texto de dichos inmuebles, mediante los cuales se puede acceder a una ficha descriptiva del inmueble o la parcela (digital o impresa) que muestra su localización y las principales características arquitectónicas e históricas (Figura 2). Junto al mapa, una leyenda dinámica en la que la información mostrada depende del nivel de zoom y las selecciones del usuario.

También es posible generar mapas temáticos en función de variables comunes a todos los inmuebles como pueden ser época de construcción, tipología arquitectónica o estado constructivo. Este tipo de mapas resulta de mucha utilidad para apreciar la evolución o distribución espacial de determinada variable sobre la totalidad del territorio.

La aplicación de Proyectos de Cooperación, por su parte, permite asociar al SIT información inherente a proyectos de cooperación internacional que se desarrollan en el Centro Histórico. También brinda la posibilidad de hacer consultas a la información cartográfica y generar mapas temáticos relacionados con este tema. 


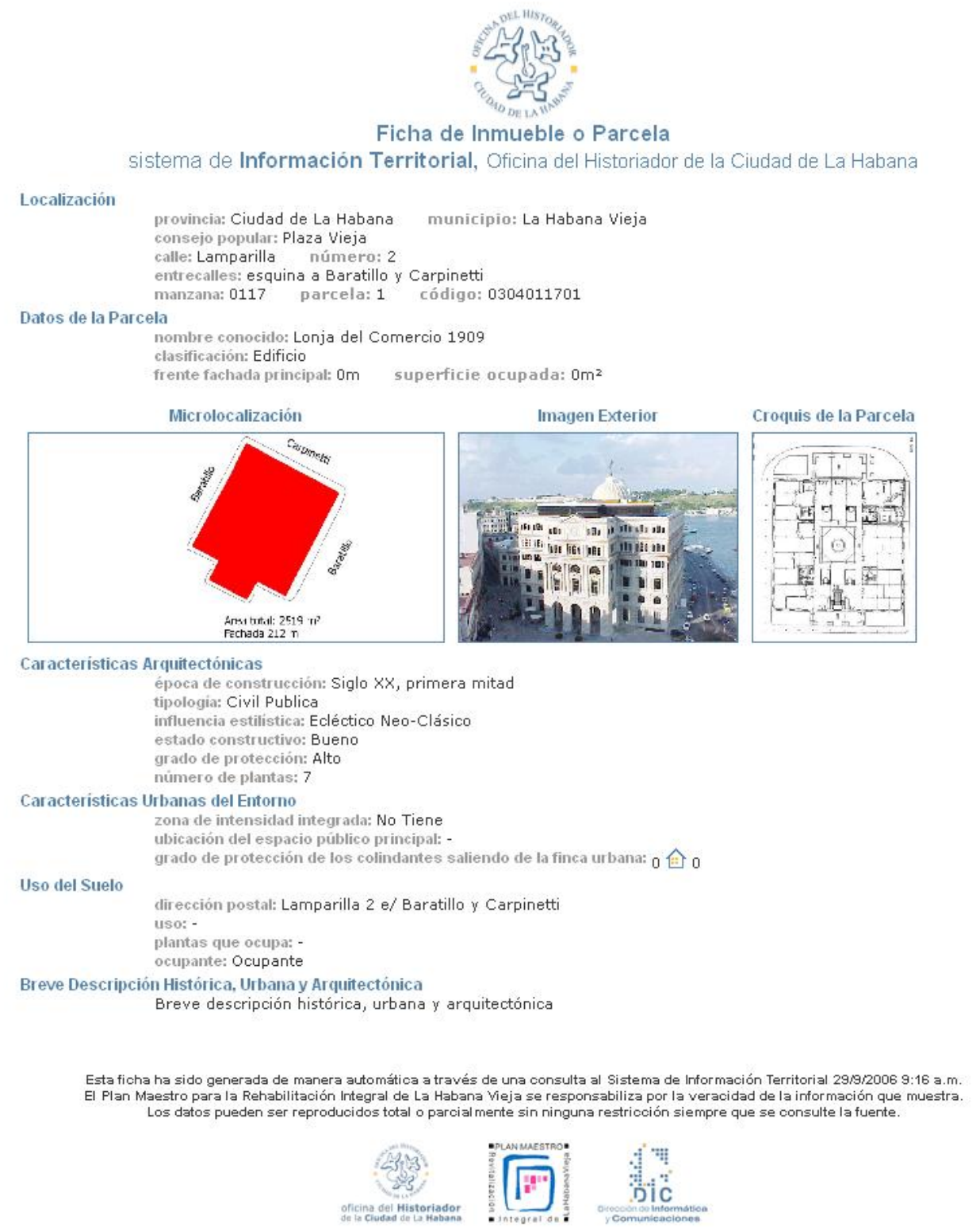

Figura 2. Ficha descriptiva de un inmueble.

Otra característica novedosa del sistema es que es capaz de analizar estadísticamente la información presente en los servidores y representarla gráficamente mediante barras de colores, diagramas por sectores, etc., tal y como se puede apreciar en la Figura 3. 


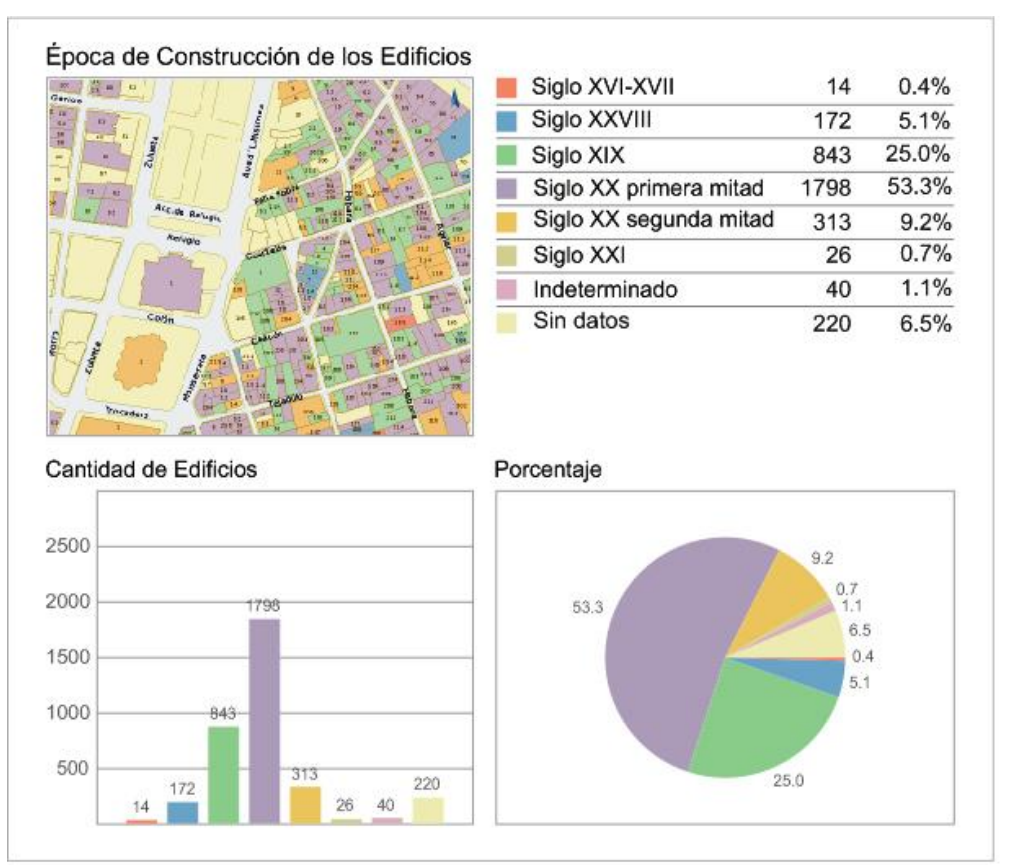

Figura 3. Ejemplo de Mapas Temáticos y Estadísticas.

\section{Arquitectura del Sistema}

El núcleo de información de todo el sistema lo compone la cartografía con todos sus datos asociados. Uno de los principales problemas que la $\mathrm{OHCH}$ se ha encontrado es que la gran mayoría de los datos que eran necesarios para alimentar el sistema estaban dispersos en varias entidades físicamente separadas, estando además en formatos diversos (SQLServer, Access, ficheros de imágenes, documentos de texto...). Había incluso datos no digitalizados.

El primer gran paso ha sido homogeneizar toda la información y evitar datos duplicados o incoherentes, por ello se está migrando a soportes comunes, en este caso PostgreSQL+PostGIS. Aprovechando la potencialidad de la Dirección de Informática y Comunicaciones se han centralizado en la misma los principales servidores del sistema. La filosofía seguida es que para cada tipo de información existe un único responsable de su gestión, pudiendo acceder a los mismos el resto de usuarios con permisos adecuados.

De esta forma en el servidor central está toda la información básica, que en un momento dado puede necesitarla cualquier entidad de la $\mathrm{OHCH}$ o un usuario externo. Ese núcleo central puede ir creciendo en función de las necesidades. Además, cada entidad gestionará los servidores de datos particulares a los que sólo podrán acceder los usuarios autorizados.

El objetivo final es que la interfaz web que percibe el usuario final se adecue a esta jerarquía de permisos de forma que la entrada principal del sistema conste de una interfaz sencilla de consulta y acceso libre, desde donde se podrá acceder a consultas y funcionalidades más exhaustivas para los usuarios que tengan los permisos adecuados. En definitiva, el sistema estará estructurado según un modelo de capas donde sobre un núcleo central, se van añadiendo capas de funcionalidades específicas que permitan hacer búsquedas o análisis sobre un mayor volumen de datos. 
La Figura 4 muestra el esquema de funcionamiento del SIT, el cual está compuesto por 3 elementos fundamentales que se encuentran ubicados en los servidores centrales de la Dirección de Informática y Comunicaciones:

- Servidor web que gestiona las peticiones de los clientes web a través de un conjunto de páginas dinámicas

- Un servidor de mapas (MapServer CGI) que devuelve el mapa en función de la consulta realizada

- Servidor de bases de datos (PostGreSQL+PostGis) que contiene tanto la información cartográfica necesaria para generar los mapas como la información alfanumérica asociada a esta.

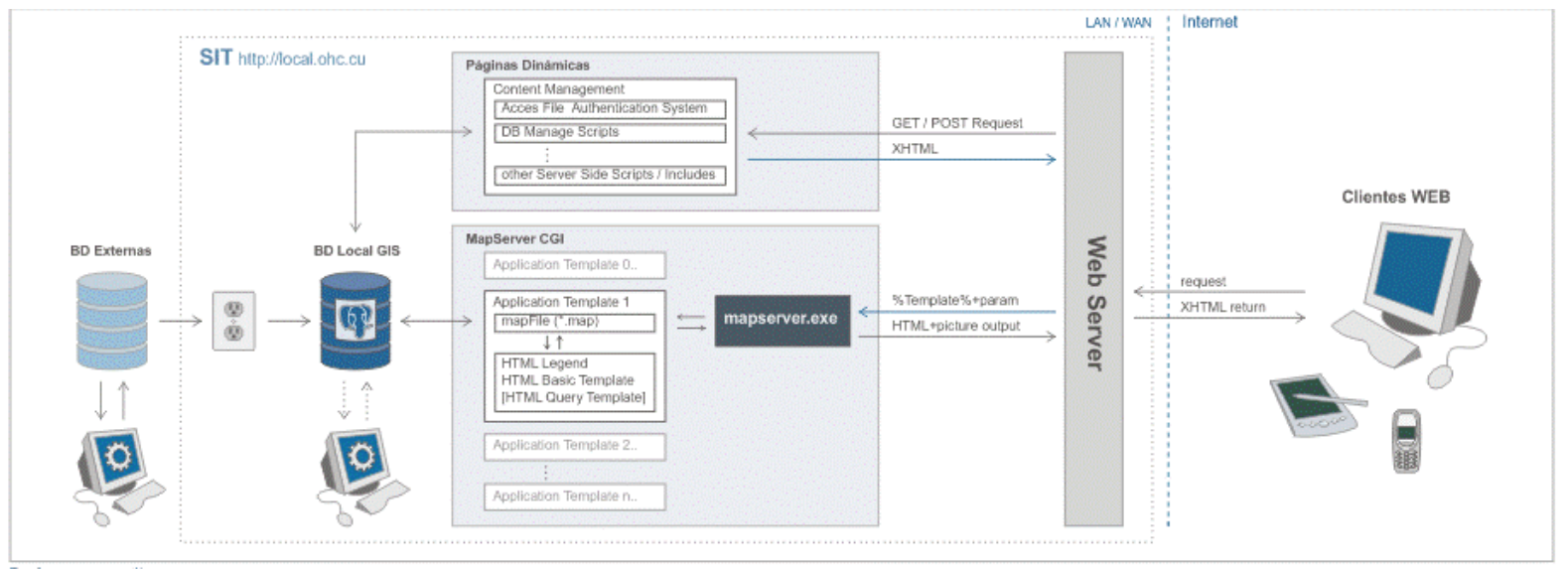

Figura 4. Arquitectura del sistema.

Debido a que la $\mathrm{OHCH}$ cuenta con una red de comunicaciones interna en desarrollo (tal y como se ha comentado en este proyecto se busca también el fortalecimiento de la misma mediante fibra óptica), se hace necesario crear mecanismos de volcado de datos desde los servidores ubicados fuera de la DIC. Este volcado se realiza semanalmente. Estos mecanismos de volcado garantizan también el cambio de formato de los datos a PostgreSQL. En el futuro, cuando las condiciones de la red de datos mejore, se prevé eliminar este paso y almacenar en los servidores centrales solo aquellos datos que sean de uso común para todas las entidades (cartografía, datos generales de los inmuebles, etc.) y que el resto de los datos esté almacenados en los servidores de la entidad responsable de generarlos y mantenerlos.

\section{Evolución del Sistema}

Aunque el sistema hasta ahora desarrollado es indudablemente de gran valor y proporciona claras ventajas a los especialistas que lo utilizan, sólo cubre una pequeña porción de las potencialidades previstas para el SIT. El objetivo es ir ampliándolo de forma gradual hasta que abarque el máximo rango posible de necesidades de la $\mathrm{OHCH}$. En particular, se pretende incorporar al sistema nuevas funcionalidades como pueden la posibilidad de realizar análisis espaciales, incorporar nuevas fuentes de datos como pueden ser datos socioeconómicos, redes técnicas, entre otros. 


\section{Conclusión}

Como conclusión, podemos decir que mediante el desarrollo de esta aplicación se ha podido verificar la utilidad del software libre para sistemas de gran envergadura. Se han utilizado las herramientas más asentadas dentro de cada ámbito (MapServer como servidor de mapas y PostreSQL con PostGIS como servidor de datos con capacidades espaciales), lo cual proporciona una garantía de continuidad debido al gran número de desarrolladores existentes y al soporte continuo que ofrecen. El rango de aplicaciones de dicho software y sus prestaciones es equiparable en muchos casos al de herramientas comerciales y su gratuidad de uso es una ventaja añadida en casos donde los recursos son limitados. Por otra parte, el sistema cuenta con la cualidad destacable de integrar información de múltiples disciplinas (patrimonio histórico, economía, aspectos sociales y administrativos, etc.) en un único entorno con gran soporte visual (mapas temáticos, gráficos, imágenes, etc.).

\section{Agradecimientos}

- Dirección de Cooperación al Desarrollo del Departamento de Vivienda y Asuntos Sociales del Gobierno Vasco, por la cofinanciación del proyecto a través del programa FOCAD.

\section{Referencias y bibliografía}

- Kropla, Hill (2005). "Beggining MapServer. Open Source GIS Development”.

- Mitchell, Tyler (2005). "Web Mapping Illustrated".

- FOSS4G: Free and Open Source Software for Geoinformatics, Internacional Conference. 12th-15th September. Lausana (Suiza). 